\title{
In Vitro Comparison of ICDAS And DIAGNOdent Pen in The Diagnosis and Treatment Decisions of Non-Cavitated Occlusal Caries
}

\section{Comparación In Vitro de ICDAS y DIAGNOdent Pen en el diagnóstico y decisiones de tratamiento de la caries oclusal no cavitada}

\author{
Serdar Akarsu DDS, PhD¹; Sultan Aktug Karademir DDS¹ \\ 1. Ordu University, Faculty of Dentistry, Department of Restorative Dentistry, Ordu, Turkey. \\ Correspondence to: Dr. Sedar Akarsu - serdarakarsu@odu.edu.tr
}

Received: $17-\mathrm{VII}-2018$

Accepted: 2-VIII-2018

Published Online First: 16-VIII-2018

D0I: https://doi.org/10.15517/ijds.v0i0.34896

\section{ABSTRACT}

The aim of this study was to compare the efficacy of the ICDAS and the DIAGNOdent Pen in the diagnosis of occlusal caries lesions without cavitation, and for basing treatment decisions on the results obtained. Eighty permanent molar teeth that were healthy and non-cavitated or that had an initial occlusal lesion were evaluated. All teeth were investigated using DIAGNOdent Pen and ICDAS by four examiners. Histological evaluation of teeth was performed using stereomicroscopy by a histologist and different experienced dentist. For evaluation of the data, weighted kappa values (kw), sensitivity, specificity, positive predictive value (PPV), negative predictive value (NPV) and likelihood ratio (LR+) values of the tests were calculated. The diagnostic results obtained using the DIAGNOdent Pen were found to correlate better with the results obtained from histological sections than those obtained using ICDAS. When the treatment decisions of the observers depending on the results of ICDAS, and ICDAS and DIAGNOdent Pen combination were compared with the decisions made based on histological examinations, the decisions based on ICDAS and DIAGNOdent Pen combined (kw: 0.522) were more accurate than the ones based on ICDAS (kw: 0.415) alone. In conclution, professional experience is an effective factor in diagnosing occlusal caries lesions without cavitation with ICDAS and in making treatment decisions for them. DIAGNOdent Pen is sufficient in diagnosing occlusal caries lesions without cavitation.

\section{KEYWORDS}

Occlusal caries; Histological examination; Laser fluorescence device; Treatment decision. 


\section{RESUMEN}

El objetivo de este estudio fue comparar la eficacia de ICDAS y de DIAGNOdent Pen en el diagnóstico de lesiones de caries oclusales no cavitadas. Ochenta molares permanentes sanos y no cavitados fueron utilizados. Todos los dientes fueron investigados usando DIAGNOdent Pen e ICDAS por cuatro examinadores. La evaluación histológica de los dientes se realizó mediante estereomicroscopía por un histólogo y por un dentista con previa experiencia. Los resultados diagnósticos obtenidos con el DIAGNOdent Pen se correlacionan mejor con los resultados obtenidos a partir de las secciones histológicas cuando comparados a los obtenidos utilizando ICDAS. Las decisiones basadas en el uso combinado de ICDAS y DIAGNOdent Pen (kw: 0.522) fueron más precisas que los basados en ICDAS (kw: 0.415). En conclusión, la experiencia profesional es un factor eficaz en diagnóstico de lesiones de caries oclusal sin cavitación con ICDAS y en la toma de decisiones de tratamiento. DIAGNOdent Pen es una herramienta confiable para diagnosticar lesiones de caries oclusales sin cavitación.

\section{PALABRAS CLAVE}

Caries oclusales; Histología; DIAGNOdent Pen.

\section{INTRODUCTION}

Though the prevalence of caries has decreased in most Western countries, the incidence of occlusal caries has increased $(1,2)$. Fluoride slows the development of enamel lesion by the well-known process of remineralization, which can mask the development of caries in dentin (3). Accordingly, non- cavitated occlusal dentine lesions may not be diagnosed by visual examination (4) . These lesions are called hidden caries or caries of fluoride $(5,6)$. The hidden caries is a major problem for dentistry because of the difficulty in standardizing the diagnosis and consequently to establish a treatment plan and prevention (7). The diagnosis of initial lesions on the occlusal surfaces is especially difficult for dentists (8). The pits and fissures on the occlusal surface do not allow access to oral hygiene assistants, and provide a convenient environment for the development of caries since they are a suitable place to trap microorganisms (9). The diagnosis of caries is important when making treatment decisions. Faulty diagnosis can lead to incorrect treatment decisions. While non-cavitated lesions can be restored later, large hidden dentin lesions can go unnoticed and restoration may not be possible later.

Correct diagnosis of caries lesions is one of the important factors for preventive treatment planning (10). Traditionally, the diagnosis of caries of the occlusal surfaces of the permanent molar teeth has been done using mirrors and probes. However, the use of probe in the diagnosis of caries is not considered optimal as it can allow the passage of cariogenic flora from the infected area to another region, and cause irreversible traumatic defect in the potential remineralization area; moreover, the results are not more accurate than with visual examination (11-13). Various researchers have visually evaluated the enamel for translucency, opacity, discoloration, and cavitation, and used the findings for the diagnosis of caries (1315). Visual examination is subjective and depends on the clinician's experience and education.

Over time, visual inspection criteria used in the past have become inadequate and new visual criteria have been developed. In 2002, the International Caries Detection and 
Assessment System (ICDAS) classification criteria were presented taking into account the most characteristic features of tooth caries. ICDAS is a clinical scoring system for dentistry education, clinical practice, and research and epidemiological studies that enables the detection and evaluation of dental caries (16-19). It is important to standardize the visual examination and prevent inconsistencies between the diagnoses of different dentists, and ICDAS provides a standardized caries diagnosis and assessment system (20). It was reorganized in 2005 and named ICDAS II. The ICDAS is a two-stage process of the diagnosis of caries on coronal tooth surfaces. The first step is to determine whether the tooth is sound, sealed, or restored. The second step is the determination of the level of caries (21).

One of the most important steps in the practice of preventive dentistry is the early diagnosis of caries lesions (9). The limitation in traditional methods has led to the development of new methods and devices to help detect caries. For this purpose, a DIAGNOdent device (KaVo, Biberach, Germany) using the principle of laser fluorescence was introduced and presented to physicians in 1998. In the following years, the deficiencies of this device became evident, and recently, the DIAGNOdent Pen (KaVo, Biberach, Germany) device has been introduced in 2005, which is more practical, smaller in size than the DIAGNOdent device and designed as a hand piece. The DIAGNOdent Pen measures the depth of the caries lesion and gives it a numerical value. The tooth surface is irradiated with a red light produced by the diode laser and transmitted to the tooth through optical fiber. The laser light is absorbed by the tooth surface and then reflected due to the fluorescence property of the tooth structure. The fluorescence intensity reflected from the demineralized area is higher than that from a strong tooth structure. Moreover, the fluorescence emitted from the metabolites (porphyrins) of bacteria in the demineralized area has a wavelength close to red light. The fluorescence is translated into numeric values, and manifests as a high number on the digital screen of the DIAGNOdent Pen. Thus, a high DIAGNOdent Pen value is obtained in deep caries lesions (22).

The performance of diagnostic tests, that is their ability to detect a person with disease or exclude a person without disease, is usually described by terms such as sensitivity, specificity, PPV (positive predictive value) and NPV (negative predictive value) (23). The sensitivity of a test is defined as the proportion of people with disease who will have a positive result. The specificity of a test is the proportion of people without the disease who will have a negative result. The positive predictive value (PPV) of a test is defined as theproportion of people with a positive test result who actually have the disease. The NPV of a test is the proportion of people with a negative test result who do not have disease (24).

The aim of this study was to compare the efficacy of the ICDAS and the DIAGNOdent Pen in the diagnosis of occlusal caries lesions without cavitation, and for basing treatment decisions on the results obtained.

\section{MATERIALS AND METHODS}

\section{PREPARATION OF SAMPLES}

Ethical approval was obtained from the Ethics Committee of the University of Ordu (2018-202). Eighty-four healthy permanent molar teeth and non-cavitated or that had an initial occlusal lesion on visual inspection using a $2.5 \times$ magnification loop were included in this in-vitro study. The teeth were kept in saline solution until examination.

The calculus and residues on the teeth were cleaned using prophylactic paste and air-water spray. Four teeth that had occlusal cavitation, hypoplastic fissures, fissure sealants, 
wide occlusal discolorations, and a proximal caries close to the marginal borders were excluded from this study. The points to be examined in the fissures were determined. The occlusal surfaces were photographed.

Four observers participated in the study. The first and second observers were dentists with 1 to 5 years of experience in the field of restorative dentisty. The third and fourth observers were dentist with 15-20 years of experience in the field of restorative dentisty. Before the study, the first and second observers were given training on ICDAS and the DIAGNOdent Pen. Apart from the teeth used in the study, ICDAS and the DIAGNOdent Pen were used by examiner 1 and examiner 2 on 10 non-cavitated molar teeth for preparation before the study.

\section{EVALUATION WITH ICDAS}

The sites determined in the occlusal region for evaluation were assessed by the four observers using the following ICDAS criteria.

- 0: Sound tooth surface: No evidence of caries after 5 sec air drying.

- 1: First visual change in enamel: Opacity or discoloration is visible at the entrance to the pit or fissure seen after prolonged air drying.

- 2: Distinct visual change in enamel visible when wet, lesion must be visible when dry.

- 3: Localized enamel breakdown in opaque or discoloured enamel.

- 4: Underlying dark shadow from dentine.

ICDAS codes were assigned to the site as follows: Code 0:"Sound"; Code 1and 2: "Enamel caries"; Code 3 and 4: "Dentine caries".

\section{EVALUATION WITH DIAGNODENT PEN}

This device was used in conjunction with the cylinder type suitable for occlusal surfaces in accordance with the manufacturer's instructions. The instrument was calibrated individually for each tooth. The DIAGNOdent Pen was placed perpendicular to the predetermined point on the occlusal surface. It was turned around its long axis to record the highest value. Three consecutive recordings were taken and the average value was recorded as the final value for this region. After one day, the four observers repeated this process. A previous study by Lussi and Hellwing was taken as reference for the DIAGNOdent Pen thresholds (DIAGNOdent PEN values 0-6: "Sound", 7-17: "Enamel caries", 18-99: "Dentin caries").

\section{HISTOLOGIC EXAMINATION}

The teeth were cut under running water with a low-speed cutting machine (Isomet, Buehler, Lake Bluff, IL, USA) in the buccolingual direction, passing through the centers of the areas evaluated with ICDAS and the DIAGNOdent Pen. Thus, the deepest region of the caries lesion was exposed. The sections obtained were evaluated using a stereomicroscope (Nikon Eclipse Ni) by a histologist and an experienced dentist at $10 \times$ magnification.

The results obtained from all evaluation methods were classified under the same groups (0: "Sound", 1: "Enamel caries", 2: "Dentin caries") for statistical analysis.

TREATMENT DECISIONS

Based on the caries diagnosis obtained by ICDAS, the treatment decision of each observer was recorded. Later, the treatment decision of each observer was recorded based on diagnosis using the DIAGNOdent Pen combined with ICDAS (0: "no treatment needed" 1: "protective fluoride application" 2: "minimally invasive approach" 3: "occlusal restoration"). Based on the depth and width of the caries lesion on histological section, the treatment decision made by a different experienced physician was accepted as the gold standard. 


\section{STATISTICAL ANALYSIS}

Statistical analysis was performed using the Number Cruncher Statistical System (NCSS) 2007 statistical software (NCSS, Utah, USA) package program. For evaluation of the data, weighted kappa values (kw) were calculated to determine the intra-observer and inter-observer accordance with respect to the number of years in the profession. Descriptive statistical methods such as frequency and percentage distributions were also used. Weighted kappa values were calculated for the agreement between ICDAS and DIAGNOdent Pen results, and histological results. Sensitivity, specificity, positive predictive value (PPV), negative predictive value (NPV), test accuracy and likelihood ratio $(L R+)$ values of the tests were calculated. The results were analyzed and significance level was set at $p<0.05$ with a confidence interval of $95 \%$.

The results were classified as follows (25):

- If $\leq 0.20$, "Poor Compatibility".

- In the range of 0.21-0.40, "Compatibility Under Average".

- In the range of 0.41-0.60, "Intermediate Compatibility".

- In the range of 0.61-0.80, "Good Compatibility". - In the range of 0.81-1.00, "Perfect Compatibility".

\section{RESULTS}

Histological evaluation revealed that out of the 80 molar teeth without occlusal surface cavitation, 16 were found to be sound, 29 had enamel caries, and 35 had dentin caries. Diagnostic results obtained using the ICDAS and DIAGNOdent Pen by the participating observers and the diagnostic results of histology are shown in Table 1.

The intra- and inter-observer weighted kappa values of the diagnostic results obtained with ICDAS and the DIAGNOdent Pen are shown in Table 2. According to the weighted kappa values, the intra-observer compatibility of the first and second observers with one to five years of experience in the profession was found to be "Compatibility Under Average." Intra-observer compatibility of the third and fourth observers with 15-20 years of professional experience was found to be "Good Compatibility". However, diagnostic results obtained using the DIAGNOdent Pen showed that the intra-observer compatibility of the four observers was at a "Perfect Compatibility." While the inter-observer compatibility of the third and fourth observers with an experience of 1520 years was high as per the weighted kappa values, the first and second observers with an experience of one to five years had lower interobserver compatibility, both when compared with themselves and with the more experienced third and fourth observers. Diagnostic results obtained using the DIAGNOdent Pen had good and perfect inter-observer compatibility levels.

The correlation of the diagnostic results obtained by the observers using ICDAS and the DIAGNOdent Pen with each other and with the histology results is shown in Table 3. While the correlation between the diagnostic results obtained using ICDAS and the DIAGNOdent Pen of the observers with 15-20 years of experience was good, it was poor for the results obtained by the observers with one to five years of experience.

The diagnostic results obtained using the DIAGNOdent Pen were found to correlate better with the results obtained from histological sections than those obtained using ICDAS.

Sensitivity, specificity, PPV, NPV, and LR values calculated by comparing the diagnostic results obtained using ICDAS and the DIAGNOdent Pen with the histological section results are shown in Table 4. It was seen that observers with 15-20 years of professional experience who diagnosed occlusal caries using ICDAS were more accurate than those with one to five years of professional 
experience in diagnosing both dentin and enamel caries. Regarding to sensitivity and specificity, diagnostic results obtained using the DIAGNOdent Pen were more accurate than those obtained using ICDAS. The possibility of enamel caries diagnosis made by ICDAS was found to be 2.06 times higher than to the no caries diagnosis ( $L R+)$. However, the possibility of an enamel caries diagnosis made by DIAGNOdent was found to be 12.14 times higher than to the no caries diagnosis.

Table 5 shows the treatment decisions made by the observers according to the diagnostic results obtained using ICDAS, ICDAS with DIAGNOdent Pen, and the histological section results. Based on the histological results, 16 out of 80 teeth with non-cavitated occlusal surface underwent "no treatment," 18 were given "fluoride application," 35 underwent "minimally invasive application," and 11 underwent "restoration." Based on histology results, fluoride treatment decisions using both ICDAS, and ICDAS and DIAGNOdent Pen combination were a success for all observers. However, experienced dentists were more successful than those inexperienced in making restoration treatment decisions. Restorative treatment decisions using the DIAGNOdent Pen in conjunction with ICDAS were also found to be more successful than restorative treatment decisions based on diagnosis using ICDAS alone.

The correspondence between the treatment decisions made as per the results of the histological section and as per the results obtained using ICDAS and DIAGNOdent Pen is shown in Table 6. According to this, the compatibility of the treatment decisions of the first and second observers with one to five years of experience based on histological sections and ICDAS results were lower than average. The compatibility between the treatment decisions made according to the diagnostic results obtained by the same observers from ICDAS and DIAGNOdent Pen, and histological sections was increased to an average level. 
Table 1. Diagnostic results obtained using the ICDAS and DIAGNOdent Pen by the participating observers and the diagnostic results of histology.

\begin{tabular}{|c|c|c|c|c|c|c|}
\hline & & & \multicolumn{2}{|c|}{ 1.Examination } & \multicolumn{2}{|c|}{ 2.Examination } \\
\hline & & & $\mathrm{n}$ & $\%$ & $\mathrm{n}$ & $\%$ \\
\hline \multirow[t]{12}{*}{ ICDAS } & Examiner 1 & Sound & 8 & 10.00 & 26 & 32.50 \\
\hline & & Enamel Caries & 51 & 63.75 & 43 & 53.75 \\
\hline & & Dentin Caries & 21 & 26.25 & 11 & 13.75 \\
\hline & Examiner 2 & Sound & 20 & 25.00 & 13 & 16.25 \\
\hline & & Enamel Caries & 47 & 58.75 & 46 & 57.50 \\
\hline & & Dentin Caries & 13 & 16.25 & 21 & 26.25 \\
\hline & Examiner 3 & Sound & 14 & 17.50 & 15 & 18.75 \\
\hline & & Enamel Caries & 34 & 42.50 & 35 & 43.75 \\
\hline & & Dentin Caries & 32 & 40.00 & 30 & 37.50 \\
\hline & Examiner 4 & Sound & 17 & 21.25 & 12 & 15.00 \\
\hline & & Enamel Caries & 26 & 32.50 & 35 & 43.75 \\
\hline & & Dentin Caries & 37 & 46.25 & 33 & 41.25 \\
\hline \multirow[t]{12}{*}{ Diagnodent Pen } & Examiner 1 & Sound & 18 & 22.50 & 16 & 20.00 \\
\hline & & Enamel Caries & 34 & 42.50 & 32 & 40.00 \\
\hline & & Dentin Caries & 28 & 35.00 & 32 & 40.00 \\
\hline & Examiner 2 & Sound & 16 & 20.00 & 18 & 22.50 \\
\hline & & Enamel Caries & 34 & 42.50 & 34 & 42.50 \\
\hline & & Dentin Caries & 30 & 37.50 & 28 & 35.00 \\
\hline & Examiner 3 & Sound & 18 & 22.50 & 16 & 20.00 \\
\hline & & Enamel Caries & 33 & 41.25 & 32 & 40.00 \\
\hline & & Dentin Caries & 29 & 36.25 & 32 & 40.00 \\
\hline & Examiner 4 & Sound & 18 & 22.50 & 16 & 20.00 \\
\hline & & Enamel Caries & 33 & 41.25 & 31 & 38.75 \\
\hline & & Dentin Caries & 29 & 36.25 & 33 & 41.25 \\
\hline \multirow[t]{3}{*}{ Histologic examination } & & Sound & 16 & 20.00 & - & - \\
\hline & & Enamel Caries & 29 & 36.25 & - & - \\
\hline & & Dentin Caries & 35 & 43.75 & - & - \\
\hline
\end{tabular}


Table 2. The intra- and inter-observer weighted kappa values of the diagnostic results obtained with ICDAS and the DIAGNOdent Pen.

\begin{tabular}{|c|c|c|c|c|}
\hline & & & KW & $\mathbf{P}$ \\
\hline \multirow[t]{8}{*}{ Intra examiner kappa values } & ICDAS & Examiner 1 & 0.257 & 0.0001 \\
\hline & & Examiner 2 & 0.244 & 0.002 \\
\hline & & Examiner 3 & 0.743 & 0.0001 \\
\hline & & Examiner 4 & 0.665 & 0.0001 \\
\hline & DIAGNOdent Pen & Examiner 1 & 0.671 & 0.0001 \\
\hline & & Examiner 2 & 0.670 & 0.0001 \\
\hline & & Examiner 3 & 0.651 & 0.0001 \\
\hline & & Examiner 4 & 0.748 & 0.0001 \\
\hline \multirow[t]{14}{*}{ Interexaminer kappa values } & ICDAS & Examiner 1/ Examiner 2 & 0.216 & 0.002 \\
\hline & & Examiner 1/ Examiner 3 & 0.238 & 0.001 \\
\hline & & Examiner 1/ Examiner 4 & 0.173 & 0.006 \\
\hline & & Examiner 2/ Examiner 3 & 0.196 & 0.006 \\
\hline & & Examiner 2/ Examiner 4 & 0.200 & 0.001 \\
\hline & & Examiner 3/ Examiner 4 & 0.664 & 0.0001 \\
\hline & & Examiner 1,2 / Examiner 3,4 & 0.204 & 0.001 \\
\hline & DIAGNOdent Pen & Examiner 1/ Examiner 2 & 0.670 & 0.0001 \\
\hline & & Examiner 1/ Examiner 3 & 0.971 & 0.0001 \\
\hline & & Examiner 1/ Examiner 4 & 0.922 & 0.0001 \\
\hline & & Examiner 2/ Examiner 3 & 0.680 & 0.0001 \\
\hline & & Examiner 2/ Examiner 4 & 0.709 & 0.0001 \\
\hline & & Examiner 3/ Examiner 4 & 0.932 & 0.0001 \\
\hline & & Examiner 1,2 / Examiner 3,4 & 0.840 & 0.0001 \\
\hline
\end{tabular}

Table 3. The correlation of the diagnostic results obtained by the observers using ICDAS and the DIAGNOdent Pen with each other and with the histology results.

\begin{tabular}{llcc}
\hline & & KW & $\mathbf{P}$ \\
\hline ICDAS/DIAGNOdent Pen & Examiner 1,2 & 0.176 & 0.001 \\
& Examiner 3,4 & 0.584 & 0.0001 \\
& All Examiners & 0.381 & 0.0001 \\
\cline { 2 - 4 } ICDAS/Histology & Examiner 1,2 & 0.233 & 0.001 \\
& Examiner 3,4 & 0.686 & 0.0001 \\
DIAGNOdent Pen/ & All Examiners & 0.451 & 0.0001 \\
\cline { 2 - 4 } Histology & Examiner 1,2 & 0.758 & 0.0001 \\
& Examiner 3,4 & 0.807 & 0.0001 \\
& All examiners & 0.782 & 0.0001 \\
\hline
\end{tabular}


Tablo 4. Sensitivity, specificity, PPV, NPV, and LR values calculated by comparing the diagnostic results obtained using ICDAS and DIAGNOdent Pen with the histological section results.

\begin{tabular}{llcccccc}
\hline & & Sensitivity & Specificity & PPV & NPV & Accuracy & LR(+) \\
\hline Histology / ICDAS & Enamel caries & 0.79 & 0.44 & 0.72 & 0.54 & 0.67 & 1.41 \\
(1-5 Years) & Dentin caries & 0.37 & 0.44 & 0.59 & 0.24 & 0.39 & 0.66 \\
Histology / ICDAS & All results & 0.54 & 0.36 & 0.72 & 0.30 & 0.49 & 0.94 \\
\cline { 2 - 7 } (15-20 Years) & Enamel caries & 0.88 & 0.75 & 0.86 & 0.77 & 0.83 & 3.52 \\
& Dentin caries & 0.87 & 0.75 & 0.88 & 0.73 & 0.83 & 3.49 \\
Histology / DIAGNOdent & All results & 0.87 & 0.60 & 0.87 & 0.60 & 0.80 & 2.17 \\
\cline { 2 - 7 } (1-5 Years) & Enamel caries & 0.97 & 0.91 & 0.95 & 0.94 & 0.94 & 10.30 \\
& Dentin caries & 0.77 & 0.91 & 0.95 & 0.64 & 0.81 & 8.23 \\
Histology / DIAGNOdent & All results & 0.85 & 0.81 & 0.94 & 0.62 & 0.84 & 4.40 \\
\cline { 2 - 7 } (15-20 Years) & Enamel caries & 0.93 & 0.91 & 0.96 & 0.83 & 0.93 & 10.24 \\
& Dentin caries & 0.81 & 0.91 & 0.97 & 0.61 & 0.84 & 8.96 \\
Histology / ICDAS & All results & 0.87 & 0.91 & 0.97 & 0.64 & 0.88 & 9.53 \\
\cline { 2 - 7 } & Enamel caries & 0.84 & 0.59 & 0.79 & 0.67 & 0.75 & 2.06 \\
& Dentin caries & 0.62 & 0.59 & 0.77 & 0.42 & 0.61 & 1.53 \\
Histology / DIAGNOdent & All results & 0.70 & 0.48 & 0.80 & 0.45 & 0.65 & 1.55 \\
\cline { 2 - 7 } & Enamel caries & 0.95 & 0.92 & 0.96 & 0.91 & 0.94 & 12.14 \\
& Dentin caries & 0.79 & 0.92 & 0.96 & 0.67 & 0.83 & 10.15 \\
& All results & 0.86 & 0.86 & 0.96 & 0.63 & 0.86 & 5.94 \\
\hline
\end{tabular}


Tablo 5. Treatment decisions made by the observers according to the diagnostic results obtained using ICDAS, ICDAS with DIAGNOdent Pen, and the histological section results.

\begin{tabular}{|c|c|c|c|c|}
\hline & & & & \\
\hline & & & $\mathbf{n}$ & $\%$ \\
\hline ICDAS & Examiner 1 & No treatment needed & 11 & 13.75 \\
\hline & & Protective fluoride application & 36 & 45.00 \\
\hline & & Minimally invasive approach & 28 & 35.00 \\
\hline & & Occlusal restoration & 5 & 6.25 \\
\hline & Examiner 2 & No treatment needed & 9 & 11.25 \\
\hline & & Protective fluoride application & 37 & 46.25 \\
\hline & & Minimally invasive approach & 26 & 32.50 \\
\hline & & Occlusal restoration & 8 & 10.00 \\
\hline & Examiner 3 & No treatment needed & 14 & 17.50 \\
\hline & & Protective fluoride application & 28 & 35.00 \\
\hline & & Minimally invasive approach & 34 & 42.50 \\
\hline & & Occlusal restoration & 15 & 18.75 \\
\hline & Examiner 4 & No treatment needed & 9 & 11.25 \\
\hline & & Protective fluoride application & 29 & 36.25 \\
\hline & & Minimally invasive approach & 27 & 33.75 \\
\hline & & Occlusal restoration & 15 & 18.75 \\
\hline DIAGNOdent Pen & Examiner 1 & No treatment needed & 17 & 21.25 \\
\hline & & Protective fluoride application & 30 & 37.50 \\
\hline & & Minimally invasive approach & 5 & 6.25 \\
\hline & & Occlusal restoration & 28 & 35.00 \\
\hline & Examiner 2 & No treatment needed & 17 & 21.25 \\
\hline & & Protective fluoride application & 28 & 35.00 \\
\hline & & Minimally invasive approach & 5 & 6.25 \\
\hline & & Occlusal restoration & 30 & 37.50 \\
\hline & Examiner 3 & No treatment needed & 15 & 18.75 \\
\hline & & Protective fluoride application & 27 & 33.75 \\
\hline & & Minimally invasive approach & 15 & 18.75 \\
\hline & & Occlusal restoration & 23 & 28.75 \\
\hline & Examiner 4 & No treatment needed & 16 & 20.00 \\
\hline & & Protective fluoride application & 26 & 32.50 \\
\hline & & Minimally invasive approach & 19 & 23.75 \\
\hline & & Occlusal restoration & 19 & 23.75 \\
\hline & Histological & No treatment needed & 16 & 20.00 \\
\hline & Examination & Protective fluoride application & 18 & 22.50 \\
\hline & & Minimally invasive approach & 35 & 43.75 \\
\hline & & Occlusal restoration & 11 & 13.75 \\
\hline
\end{tabular}


Table 6. The correspondence between the treatment decisions made as per the results of the histological section and as per the results obtained using ICDAS and DIAGNOdent Pen.

\begin{tabular}{llcc}
\hline & & $\mathrm{KW}$ & $\mathrm{P}$ \\
\hline Histology/ & Examiner 1,2 & 0.282 & 0.001 \\
ICDAS & Examiner 3,4 & 0.550 & 0.0001 \\
& All examiners & 0.415 & 0.0001 \\
Histology/ & Examiner1,2 & 0.413 & 0.0001 \\
DIAGN0dent & Examiner 3,4 & 0.637 & 0.0001 \\
Pen & All examiners & 0.522 & 0.0001 \\
\hline
\end{tabular}

\section{DISCUSSION}

Correct diagnosis of the presence or absence of disease is a fundamental requirement of health care. The diagnosis of occlusal caries in the absence of cavities is difficult and diagnostic uncertainties can impact treatment decisions. The development of more precise, specific, and repeatable diagnostic tools for occlusal surfaces can greatly contribute to the more precise planning of preventive and restorative treatment.

While the intra-observer repeatability of ICDAS in occlusal caries diagnosis studies using ICDAS and the DIAGNOdent Pen have been shown to be kw: 0.74-0.99 (26-31), the intra-observer repeatability of the DIAGNOdent Pen in occlusal caries is reported to be kw: 0.79-0.98 (27-30, 32-36). Intra-observer repeatability of ICDAS in our study was kw: $0.257-0.743$ and that of the DIAGNOdent Pen was kw: 0.651-0.748. These values are lower than the intra-observer repeatability values in previously published studies. The reason for this might be that while the observers in those studies were experienced dentists, in our study, observers with one to five years of experience had not used the ICDAS criteria before and only took a one-day course before the study. Moreover, the time period between the first and second measurements might be another factor affecting the diagnostic results.
Table 3 shows the relationship between the diagnostic results of ICDAS and DIAGNOdent Pen and that of histology. The agreement between the results of the DIAGNOdent Pen and histology was better than that between the results of ICDAS and histology. This situation can be explained by the fact that ICDAS is a subjective test that shows variation depending on the illumination setting and the visual perception of the observer (37), whereas the DIAGNOdent Pen is an objective method to quantitatively assess the area examined (38).

The kappa coefficient, which is very important to assess the repeatability of diagnostic methods, is used to measure the inter-rater agreement between categorical data. Repeatability, however, may not always be important because a repeatable diagnostic method could also be faulty. So, sensitivity and specificity values are also important to evaluate a diagnostic method (39). In previous studies, the sensitivity for ICDAS ranged from 0.73 to 1 and the specificity ranged from 0.49 to $0.91(30,32,33,40,41)$. These results are similar to sensitivity $(0.87)$ and specificity $(0.60)$ values for ICDAS among observers with 15-20 years of professional experience in our study. However, the sensitivity (0.54) and specificity (0.36) values for ICDAS in observers with one to five years of professional experience were lower.

In earlier studies, the sensitivity of the DIAGNOdent Pen varied between $0.33-1$ and the specificity between $0.49-0.97$ (30,32,33,40-44). Our results were similar. Sensitivity $(0.86)$ and specificity (0.86) values of DIAGNOdent Pen were higher than that of ICDAS. Even if the design of the study was in-vitro, they are several limitations regarding study comparability, mainly due to the potential confounders associated to the specific methodology employed. The variability of sensitivity and specificity values of the DIAGNOdent Pen may be due to the differences in the solutions in which the extracted teeth were held, the duration for which they were held, the holding temperature, 
the calibration of the device, and the differences between the threshold values (42). In addition, the PPV of ICDAS and the DIAGNOdent Pen were 0.80 and 0.96 , respectively, and the NPV of ICDAS and the DIAGNOdent Pen were 0.45 and 0.63 , respectively. The PPV and NPV describe the performance of a diagnostic test and they depend on the prevalence of the disease tested. When the prevalence increases, PPV increases and NPV decreases. This is capital when analyzing caries, since its prevalence is rather high in all populations across the world (17).

When the treatment decisions of the observers depending on the results of ICDAS, and ICDAS and DIAGNOdent Pen combination were compared with the decisions made based on histological examinations, the decisions based on ICDAS and DIAGNOdent Pen combined (kw: 0.522) were more successful than the ones based on ICDAS (kw: 0.415) alone. Observers with professional experience of one to five years made a treatment decision of restoration for five out of 35 cases based on ICDAS (which were diagnosed as dentin caries after histological examination), whereas the number was 28 when ICDAS and DIAGNOdent Pen were used together. It is natural that there will be variability in the treatment of occlusal caries depending on the diagnosis made by the dentist. Nevertheless, even when the diagnoses are similar, there may be variations in treatment modalities chosen (45). Assessment of lesion activity, in particular, is essential to make the choice between preventive applications and restorative treatment. However, since ours was an in vitro study, lesion activity was not taken into consideration when the treatment decision was made.

There are many reasons for these differences in treatment decisions. Correct diagnosis of caries is the most important one. Factors such as age, experience, and educational status of the dentists also influence the decision-making process (46).

Conventional methods of diagnosing dental decay, such as use of the dental explorer or bitewing radiographs, are often ineffective in detecting enamel defects, as they may be too small or inaccessible to the diagnostic tool (47).

Although using sharp explorers can better distinguish between standards of different roughness (48). They have been pointed out as inappropriate tools for assessing dental lesions because they can irreversibly damage enamel. Despite this fact, many dentists still use these tools for tactile examinations $(49,50)$. Early caries diagnosis is a key factor in the prevention and management of dental caries. The change in the paradigm to minimally invasive dentistry has ascertained the field of dentistry to a more preventive approach to caries management, which demands a proper caries risk assessment and an early detection of caries It is recommended that the laser device is used in the decision making process in relation to the diagnosis of occlusal caries as a second opinion in cases of doubt after visual inspection (51).

\section{CONCLUSIONS}

Professional experience is an effective factor in diagnosing occlusal caries lesions without cavitation with ICDAS and in making treatment decisions for them. DIAGNOdent Pen (Kavo, Biberach, Germany) is more accurate than ICDAS in diagnosing occlusal caries lesions without cavitation. DIAGNOdent is an appropriate modality for occlusal caries detection as a complementary method beside other methods as ICDAS and radiographic methods. The use of ICDAS and DIAGNOdent Pen (Kavo, Biberach, Germany) combination is the best procedure when treating and deciding on the appropriate treatment 
for occlusal lesions without cavitation which involves dentine.

\section{ACKNOWLEDGMENTS}

None of the authors has financial interest related to this study to disclosure.

\section{CONFLICT OF INTEREST}

The authors declare that they have no conflict of interest.

\section{REFERENCES}

1. Mejare I., Källestål C., Stenlund H., Johansson H. Caries Development from 11 to 22 Years of Age: A Prospective Radiographic StudyPrevalence and Distribution. Caries research. 1998; 32 (1): 10-6.

2. Mejàre I., Stenlund H., Zelezny-Holmlund C. Caries incidence and lesion progression from adolescence to young adulthood: a prospective 15-year cohort study in Sweden. Caries research. 2004; 38 (2): 130-41.

3. Lussi A. Comparison of different methods for the diagnosis of fissure caries without cavitation. Caries Research. 1993; 27 (5): 409-16.

4. Weerheijm K. Occlusal'hidden caries'. Dental update. 1997; 24 (5): 182-4.

5. Thomas M. F., Ricketts D. N., Wilson R. F. Occlusal caries diagnosis in molar teeth from bitewing and panoramic radiographs. Primary Dental Care. 2001; 8 (2): 63-9.

6. Lagerweij M., Ten Cate J. Remineralisation of enamel lesions with daily applications of a high-concentration fluoride gel and a fluoridated toothpaste: an in situ study. Caries research. 2002; 36 (4): 270-4.

7. Weerheijm K., Eggink C. The clinical diagnosis of occlusal caries: a problem.
ASDC journal of dentistry for children. 1989; 56 (3): 196-200.

8. Bader J. D., Shugars D. A. A systematic review of the performance of a laser fluorescence device for detecting caries. The Journal of the American Dental Association. 2004; 135 (10): 1413-26.

9. Fontana M., Young D. A., Wolff M. S., Pitts N. B., Longbottom C. Defining dental caries for 2010 and beyond. Dental Clinics. 2010; 54 (3): 423-40.

10. Gomez J., editor Detection and diagnosis of the early caries lesion. BMC oral health; 2015: BioMed Central.

11. Braun A., Guiraud L. M. J. C., Frankenberger R. Histological validation of ICDAS II and radiological assessment of occlusal carious lesions in permanent teeth. Odontology. 2017; 105 (1): 46-53.

12. Ismail A. I. Clinical diagnosis of precavitated carious lesions. Community dentistry and oral epidemiology. 1997; 25 (1): 13-23.

13. Nyvad B., Baelum V. Nyvad criteria for caries lesion activity and severity assessment: a validated approach for clinical management and research. Caries research. 2018; 52 (5): 397-405.

14. Melo M., Pascual A., Camps I., del Campo Á., Ata-Ali J. Caries diagnosis using light fluorescence devices in comparison with traditional visual and tactile evaluation: A prospective study in 152 patients. Odontology. 2017; 105 (3): 283-90.

15. Ekstrand K. R., Gimenez T., Ferreira F. R., Mendes F. M., Braga M. M. The International Caries Detection and Assessment SystemICDAS: A Systematic Review. Caries research. 2018; 52 (5): 406-19.

16. Braga M., Oliveira L., Bonini G., Bönecker M., Mendes F. Feasibility of the International Caries Detection and Assessment System (ICDAS-II) in epidemiological surveys and 
comparability with standard World Health Organization criteria. Caries research. 2009; 43 (4): 245-9.

17. Chu Ch., Chau A., Lo E. Current and future research in diagnostic criteria and evaluation of caries detection methods. Oral Health Prev Dent. 2013; 11 (2): 181-9.

18. Ismail A., Sohn W., Tellez M., Amaya A., Sen A., Hasson H., et al. The International Caries Detection and Assessment System (ICDAS): an integrated system for measuring dental caries. Community dentistry and oral epidemiology. 2007; 35 (3): 170-8.

19. Pitts N. " ICDAS"--an international system for caries detection and assessment being developed to facilitate caries epidemiology, research and appropriate clinical management. Community dental health. 2004; 21 (3): 193.

20. Pitts N., Stamm J. International Consensus Workshop on Caries Clinical Trials (ICWCCT)-final consensus statements: agreeing where the evidence leads. Journal of dental research. 2004; 83 (1_suppl): 125-8.

21. Dikmen B. Icdas II criteria (international caries detection and assessment system). Journal of Istanbul University Faculty of Dentistry. 2015; 49 (3): 63.

22. Lussi A., Hibst R., Paulus R. DIAGNOdent: an optical method for caries detection. Journal of Dental Research. 2004; 83 (1_suppl): 80-3.

23. Steurer J., Fischer J. E., Bachmann L. M., Koller M., ter Riet G. Communicating accuracy of tests to general practitioners: a controlled study. Bmj. 2002; 324 (7341): 824-6.

24. Akobeng A. K. Understanding diagnostic tests 1: sensitivity, specificity and predictive values. Acta paediatrica. 2007; 96 (3): 338-41.

25. Landis J. R., Koch G. G. The measurement of observer agreement for categorical data. biometrics. 1977:159-74.

26. Attrill D., Ashley P. Diagnostics: Occlusal caries detection in primary teeth: a comparison of DIAGNOdent with conventional methods. British Dental Journal. 2001; 190 (8): 440.
27. Oancea R., Podariu A. C., Vasile L., Rosianu R., Folescu R. In vitro evaluation of laser fluorescence devices for caries detection through stereomicroscopic imaging. Rom J Morphol Embryol. 2013; 54 (2): 333-41.

28. Heinrich-Weltzien R., Weerheijm K. L., Kühnisch J., Oehme T., Stösser L. Clinical evaluation of visual, radiographic, and laser fluorescence methods for detection of occlusal caries. Journal of Dentistry for Children. 2002; 69 (2): 127-32.

29. Pinelli C., Serra M. C., Loffredo LdCM. Validity and reproducibility of a laser fluorescence system for detecting the activity of white-spot lesions on free smooth surfaces in vivo. Caries research. 2002; 36 (1): 19-24.

30. Kockanat A., Unal M. In vivo and in vitro comparison of ICDAS II, DIAGNOdent pen, CarieScan PRO and SoproLife camera for occlusal caries detection in primary molar teeth. European journal of paediatric dentistry: official journal of European Academy of Paediatric Dentistry. 2017; 18 (2): 99-104.

31. Bakhshandeh A., Ekstrand K., Qvist V. Measurement of histological and radiographic depth and width of occlusal caries lesions: a methodological study. Caries research. 2011; 45 (6): 547-55.

32. Iranzo-Cortés J. E., Terzic S., Almerich-Silla J. M. Diagnostic validity of ICDAS and DIAGNOdent combined: an in vitro study in pre-cavitated lesions. Lasers in medical science. 2017; 32 (3): 543-8.

33. Achilleos E.-E., Rahiotis C., Kakaboura A., Vougiouklakis G. Evaluation of a new fluorescence-based device in the detection of incipient occlusal caries lesions. Lasers in medical science. 2013; 28 (1): 193-201.

34. Shi X.-Q., Welander U., Angmar-Månsson B. Occlusal caries detection with KaVo DIAGNOdent and radiography: an in vitro comparison. Caries research. 2000; 34 (2): 151-8.

35. Hamishaki K. S., Chiniforush N., Monzavi A., Khazarazifard M. J. An in vivo comparison of 
two diagnostic methods in secondary caries detection. Journal of dentistry (Tehran, Iran). 2014; 11 (1): 17.

36. Jablonski-Momeni A., Stachniss V., Ricketts D., Heinzel-Gutenbrunner M., Pieper K. Reproducibility and accuracy of the ICDASII for detection of occlusal caries in vitro. Caries research. 2008; 42 (2): 79-87.

37. Ari T., Kofman S. H., Ari N. In vitro evaluation of magnification and LED illumination for detection of occlusal caries in primary and permanent molars using ICDAS Criteria. Dentistry Journal. 2013;1 (3): 19-30.

38. Angnes V., Angnes G., Batisttella M., Grande R., Loguercio A., Reis A. Clinical effectiveness of laser fluorescence, visual inspection and radiography in the detection of occlusal caries. Caries Research. 2005; 39 (6): 490-5.

39. Kouchaji C. Comparison between a laser fluorescence device and visual examination in the detection of occlusal caries in children. The Saudi dental journal. 2012; 24 (3-4): 169-74.

40. Castilho L. S., Cotta F., Bueno A. C., Moreira A. N., Ferreira E. F., Magalhães C. S. Validation of DIAGNOdent laser fluorescence and the International Caries Detection and Assessment System (ICDAS) in diagnosis of occlusal caries in permanent teeth: an in vivo study. European journal of oral sciences. 2016; 124 (2): 188-94.

41. Rodrigues J., Hug I., Diniz M., Lussi A. Performance of fluorescence methods, radiographic examination and ICDAS II on occlusal surfaces in vitro. Caries research. 2008; 42 (4): 297-304.

42. Souza J., Boldieri T., Diniz M., Rodrigues J., Lussi A., Cordeiro RdCL. Traditional and novel methods for occlusal caries detection: performance on primary teeth. Lasers in medical science. 2013; 28 (1): 287-95.

43. Chu C., Lo E., You D. Clinical diagnosis of fissure caries with conventional and laserinduced fluorescence techniques. Lasers in medical science. 2010; 25 (3): 355-62.

44. Aktan A. M., Cebe M. A., Çiftçi M. E., Karaarslan E. Ş. A novel LED-based device for occlusal caries detection. Lasers in medical science. 2012; 27 (6): 1157-63.

45. Makhija S. K., Robinson M. E., Bader J. D., Shugars D. A., Litaker M. S., Im H. R., et al. Dentists' decision strategies for suspicious occlusal caries lesions in a National Dental PBRN study. Journal of dentistry. 2017.

46. SchulteA. G., Pitts N. B., Huysmans M., Splieth C., Buchalla W. European Core Curriculum in Cariology for undergraduate dental students. Caries research. 2011; 45 (4): 336-45.

47. Lussi A. Validity of diagnostic and treatment decisions of fissure caries. Caries research. 1991; 25 (4): 296-303.

48. Ando M., Eckert G., Zero D. Preliminary study to establish a relationship between tactile sensation and surface roughness. Caries research. 2010; 44 (1): 24-8.

49. Kühnisch J., Dietz W., Stösser L., Hickel R., Heinrich-Weltzien R. Effects of dental probing on occlusal surfaces-a scanning electron microscopy evaluation. Caries research. 2007; 41 (1): 43-8.

50. Ekstrand K., Qvist V., Thylstrup A. Light microscope study of the effect of probing in occlusal surfaces. Caries research. 1987; 21 (4): 368-74.

51. Lussi A., Megert B., Longbottom C., Reich E., Francescut P. Clinical performance of a laser fluorescence device for detection of occlusal caries lesions. European Journal of Oral Sciences. 2001; 109 (1): 14-9. 